\title{
Analisis Daerah Rawan Kecelakaan (Black Site) Dan Titik Rawan Kecelakaan (Black Spot) Provinsi Lampung
}

\author{
Yogi Oktopianto*1, Siti Shofiah ${ }^{2}$, Faishal Andhi Rokhman ${ }^{3}$, Kanthi Pangestu \\ Wijayanthi $^{4}$, Eka Krisdayanti ${ }^{5}$ \\ ${ }^{1,3,4}$ Program Studi Manajemen Keselamatan Transportasi Jalan, \\ Politeknik Keselamatan Transportasi Jalan, Tegal \\ ${ }^{2}$ Program Studi Pengujian Kendaraan Bermotor, Politeknik Keselamatan Transportasi Jalan, Tegal \\ E-mail: *yogi.oktopianto@pktj.ac.id
}

Received 14 January 2021; Reviewed 27 January 2021; Accepted 04 April 2021

Journal Homepage: http://jurnal.borneo.ac.id/index.php/borneoengineering

\begin{abstract}
Traffic accidents are the main indicator of road safety levels. There were 2,225 traffic accidents throughout 2019 in Lampung Province with 724 deaths, 1240 seriously injured, and 2015 minor injuries. The research was conducted to the identification of the black site and black spot in Lampung Province. The method used in this research is the EAN, Z-score, Frequency of accidents method calculates accident-prone areas to get the value of the accident location (Black Site) and the Cumulative Summary method to identify the black spot. The results showed from 93 roads, there is 1 road which is the highest black link of each road status. The accident-prone area (black site) is Jalan Lintas Tengah Sumatra and accident-prone points (black spot) at KM 18-26 are influenced by land use, road geometric, and traffic signs.
\end{abstract}

Keywords: Black Site, Black spot, Accident-Prone Areas, EAN, Z-Score

\begin{abstract}
Abstrak
Kecelakaan lalu lintas merupakan indikator utama tingkat keselamatan jalan raya. Kecelakaan lalu lintas sepanjang tahun 2019 di Provinsi Lampung sebanyak 2225 kejadian kecelakaan dengan korban meninggal 724 jiwa, korban mengalami luka berat sebanyak 1240 jiwa, korban mengalami luka ringan sebanyak 2015 jiwa. Penelitian dilakukan untuk mengetahui daerah rawan kecelakaan (black site) dan titik rawan kecelakaan (black spot) di provinsi lampung. Metode yang digunakan dalam penelitian ini meliputi metode EAN, Z-Score, Frekuensi Kecelakaan untuk menganalisis penentuan daerah rawan kecelakaan dan metode Cumulative Summary untuk menganalisis titik rawan kecelakaan. Hasil penelitian menunjukkan dari 93 ruas jalan terdapat 1 ruas jalan yang merupakan black link tertinggi di setiap status ruas jalan. Daerah rawan kecelakaan (black site) adalah Jalan Lintas Tengah Sumatera dan titik rawan kecelakaan (black spot) di KM 18-26 yang dipengaruhi oleh penggunaan lahan, geometri jalan dan rambu lalu lintas.
\end{abstract}

Kata kunci: Black Site, Black spot, Daerah Rawan Kecelakaan, EAN, Z-Score

\section{Pendahuluan}

Kecelakaan lalu lintas adalah suatu peristiwa yang terjadi di jalan secara tidak terduga dan tidak disengaja yang melibatkan suatu kendaraan dengan kendaraan yang lain ataupun dengan manusia 
yang mengakibatkan korban jiwa dan kerugian harta benda. Keselamatan jalan raya di era yang semakin modern ini merupakan salah satu masalah yang penting untuk diperhatikan. Peningkatan jumlah kendaraan yang beroperasi di jalan tidak seimbang dengan peningkatan kesadaran dalam berkendara sehingga semakin memperparah masalah transportasi (Rahmawaty et al., 2020). Dengan pesatnya perkembangan ekonomi dan urbanisasi, jumlah kendaraan bermotor perkotaan terus meningkat. Perjalanan perkotaan memang lebih nyaman, tetapi masalah keselamatan lalu lintas semakin menonjol (Fan et al., 2019). Namun hal ini tidaklah sederhana, karena dalam sistem transportasi jalan raya melibatkan tiga unsur utama yaitu manusia, sarana transportasi dan prasarana transportasi (Hidayat \& Oktopianto, 2020).

Kecelakaan lalu lintas sepanjang tahun 2019 di Provinsi Lampung sebanyak 2.225 kejadian kecelakaan dengan korban meninggal 724 jiwa, korban mengalami luka berat sebanyak 1240 jiwa, korban mengalami luka ringan sebanyak 2015 jiwa, serta jumlah kerugian materiil yaitu Rp 12.924.880.000,- (Direktorat Lalu Lintas Polda Lampung, 2020). Berdasarkan data kecelakaan tersebut, maka dapat diperoleh titik-titik yang menjadi daerah rawan kecelakaan lalu lintas. Penentuan daerah rawan kecelakaan lalu lintas dapat menggunakan metode yang dapat digunakan seperti frekuensi kecelakaan, cussum, z-score, dan EAN. Karakteristik daerah rawan kecelakaan (black site) dan titik rawan kecelakaan (black spot) lalu lintas dipengaruhi oleh penggunaan lahan, geometrik jalan, volume lalu lintas, kapasitas jalan, dan rambu lalu lintas (Isa Al Qurni, 2016). Informasi mengenai daerah rawan kecelakaan sangat dibutuhkan oleh masyarakat dan penegak hukum. Informasi tersebut dapat dijadikan bahan pertimbangan untuk pengawasan maupun tindakan antisipasi khususnya bagi kepolisian (Arumsari et al., 2016).

Kecelakaan lalu lintas merupakan masalah utama di seluruh dunia. Salah satu penyebab utama kecelakaan lalu lintas adalah perilaku mengemudi yang dipengaruhi oleh kondisi lalu lintas dan parameter infrastruktur lainnya (Gregoriades \& Mouskos, 2013). Kecelakaan lalu lintas jalan raya disebabkan oleh beberapa faktor yang berhubungan dengan sistem lalu lintas: pengguna jalan raya, lingkungan jalan raya dan kendaraan. Temuan pada penelitian sebelumnya menunjukkan bahwa pejalan kaki merupakan korban tertinggi dalam jumlah korban tewas atau terluka parah, diikuti oleh penumpang dan pengemudi (W/Yohannes \& Minale, 2015). Oleh karena itu, agar efektif sebagai salah satu tindakan penanggulangan keselamatan mendatang, metode tersebut harus mengintegrasikan pertimbangan dari rekayasa lalu lintas, psikologi pengemudi, dan perilaku kendaraan. Metode manajemen keselamatan lalu lintas terintegrasi dengan mekanisme yang dapat melacak kejadian kecelakaan, bagaimana kendaraan berperilaku dan terakhir risiko kecelakaan apa yang meningkat sebagai rangkaian kejadian (Wakabayashi et al., 2014). Identifikasi ruas jalan yang ditandai dengan kecelakaan berisiko tinggi adalah langkah pertama untuk setiap proses manajemen keselamatan jalan yang berhasil, dengan mempertimbangkan keterbatasan sumber daya yang tersedia (Ghadi \& Török, 2017).

Kecelakaan lalu lintas disebabkan oleh kesalahan manusia 66,67\%, kegagalan kendaraan 11,11\% dan, buruknya kondisi teknis jalan eksisting $22,22 \%$. Setelah menerapkan 3 strategi yang meliputi mendidik pengguna jalan, meningkatkan strategi jalan yang lebih aman, dan meningkatkan keselamatan jalan dan spesifikasi teknis, angka kecelakaan menurun hingga 50\% (Sandhyavitri et al., 2017). Untuk kepentingan penanggulangannya diperlukan adanya suatu pola yang dapat menggambarkan karakteristik proses kejadian suatu kecelakaan lalu lintas, agar dapat disimpulkan faktor penyebabnya supaya dapat dirumuskan pula upaya penanggulangannya, seperti penelitian sebelumnya hasil analisa didapatkan faktor-faktor kecelakaan pada ruas jalan By-Pass Krian Balongbendo adalah faktor manusia (79,91\%), faktor kendaraan (12,66 \%), faktor jalan $(4,37 \%)$ dan faktor lingkungan $(3,06 \%)$ (Utomo, 2012). Hasil analisis data kecelakaan di Indonesia pada tahun 2012 tipe kendaraan yang paling banyak terlibat dalam kecelakaan adalah sepeda motor $(65 \%)$. Karakteristik pelaku dan korban kecelakaan yang didominasi oleh usia produktif (71\%), berjenis kelamin laki-laki $(>53 \%)$, berprofesi sebagai karyawan swasta $(>54 \%)$ dan tingkat pendidikan yang masih SLTA $(>51 \%)$. Penyebab kecelakaan terdiri dari faktor manusia (kurang tertib), faktor kendaraan (rem blong sebanyak 27\%), jalan (kurangnya fasilitas keselamatan dijalan 
sebanyak 50\%) dan lingkungan (hujan 51\%). Waktu kejadian kecelakaan yang paling banyak terjadi 06.00-18.00 sebanyak 62\%. Lokasi rawan kecelakaan terjadi pada daerah yang memiliki kecepatan ijin yang tinggi dan hambatan samping yang besar seperti jalan arteri 38\%, jalan kabupaten (38\%) dan kawasan permukiman (77\%). Tipe pergerakan kendaraan yang paling banyak menyebabkan kecelakaan yaitu tabrakan depan-depan (24\%) dan depan-samping (22\%) (Herawati, 2019). Metode yang di gunakan untuk menentukan lokasi titik rawan kecelakaan (black spot) adalah suatu lokasi di mana tingkatan kecelakaan tinggi dengan kejadian kecelakaan di KM yang sama yang di akibatkan oleh suatu penyebab tertentu (Zulhendra, 2015).

Faktor dominan kecelakaan yaitu disebabkan oleh manusia. Tindakan yang dapat dilakukan untuk mengurangi kecelakaan pada lokasi titik rawan kecelakaan yaitu dengan membandingkan kondisi ruas jalan yang rawan kecelakaan dengan ruas jalan tingkat kecelakaan rendah, sehingga dapat diambil tindakan teknis. Solusi mengurangi kecelakaan dengan pemasangan rambu, rumble strip dan perbaikan jalanan (Khomeini \& Taufik, 2017).

Selanjutnya, analisis keselamatan jalan dapat dilakukan sebagai upaya untuk mengetahui penanganan yang tepat terhadap daerah rawan kecelakaan lalu lintas. Masalah kecelakaan lalu lintas menjadi suatu hal yang vital yang perlu dilakukan kajian terhadapnya, baik mengenai penyebab, akibat, dan penanganannya. Tujuan dari penelitian ini untuk mengidentifikasi lokasi rawan kecelakaan yang berupa titik rawan kecelakaan lalu lintas di Provinsi Lampung.

\section{Metode Penelitian}

Lokasi penelitian ini di 13 kabupaten dan 1 kota yang ada di Provinsi Lampung yang meliputi 93 ruas jalan. Penelitian ini menggunakan penelitian kuantitatif dengan mendapatkan data melalui data primer dan sekunder yang digunakan sebagai bahan analisis data. Tahapan yang dilakukan dalam penelitian ini adalah:

1. Studi literatur, yaitu untuk melakukan tinjauan terkait identifikasi lokasi rawan kecelakaan yang berupa titik rawan kecelakaan lalu lintas

2. Pengumpulan data, pengumpulan data meliputi data primer yang merupakan data yang langsung didapatkan di lapangan dan data sekunder yang merupakan data yang didapatkan dari sumber. Data primer dan data sekunder dalam penelitian ini yaitu:

a. Data primer meliputi Survei inventarisasi jalan dilakukan dengan maksud untuk mengetahui kondisi ruas jalan di wilayah studi. Kondisi yang diamati adalah meliputi Panjang ruas, lebar, perkerasan jalan, tipe jalan, fasilitas dan perlengkapan jalan yang ada seperti rambu dan marka jalan. Survei Konflik Lalu Lintas, ini dimaksudkan untuk mengetahui pola pergerakan kendaraan yang menyebabkan kecelakaan lalu lintas.

b. Data sekunder yaitu berupa data dari Balai Pengelola Transportasi Darat (BPTD) Wilayah VI Bengkulu dan Lampung yang terdiri dari data dibidang lalu lintas, yaitu data LHRT dan kapasitas ruas jalan meliputi jalan nasional, jalan provinsi dan jalan kabupaten dan peta jaringan jalan Provinsi Lampung. Data dibidang sarana dan prasarana, yaitu data perlengkapan jalan. Data kecelakaan dari kepolisian selama 6 Tahun terakhir (2015-2020) yang terjadi di Provinsi Lampung.

3. Analisis data, yaitu meliputi analisis penentuan daerah rawan kecelakaan menggunakan metode EAN, Z-Score, dan Frekuensi Kecelakaan.

EAN dihitung dengan menjumlahkan kejadian kecelakaan pada setiap kilometer panjang jalan kemudian dikalikan dengan nilai bobot sesuai tingkat keparahan. Z-Score adalah bilangan "z" atau bilangan standar atau bilangan baku. Bilangan " $\mathrm{z}$ " dicari dari sampel yang berukuran $\mathrm{n}$, dengan data-data $\mathrm{X} 1, \mathrm{X} 2, \mathrm{X} 3, \ldots \ldots . \mathrm{Xn}$ dengan rata-rata $\mathrm{X}$ pada simpangan baku "S", sehingga dapat dibentuk data baru yaitu $\mathrm{z} 1, \mathrm{z} 2, \mathrm{z} 3, \ldots \ldots . . \mathrm{zn}$ dengan rata-rata 0 simpangan baku 1 . Dengan kata lain, nilai $\mathrm{z}$ dapat dikatakan seberapa standar deviasi jauh jarak nilai suatu data dengan nilai mean nya. Frekuensi kecelakaan sama dengan jumlah kecelakaan lalu lintas per satuan waktu 
atau per lokasi. Analisa yang digunakan dalam metode frekuensi adalah dengan membandingkan antara jumlah kejadian kecelakaan dengan rata-rata kecelakaan, jika jumlah kejadian kecelakaan lebih tinggi dari rata-ratanya maka ruas jalan tersebut dikatakan blacksite, sebaliknya jika jumlah kejadian kecelakaan pada suatu ruas tidak lebih tinggi dari rata-ratanya maka dikatakan bukan blacksite.

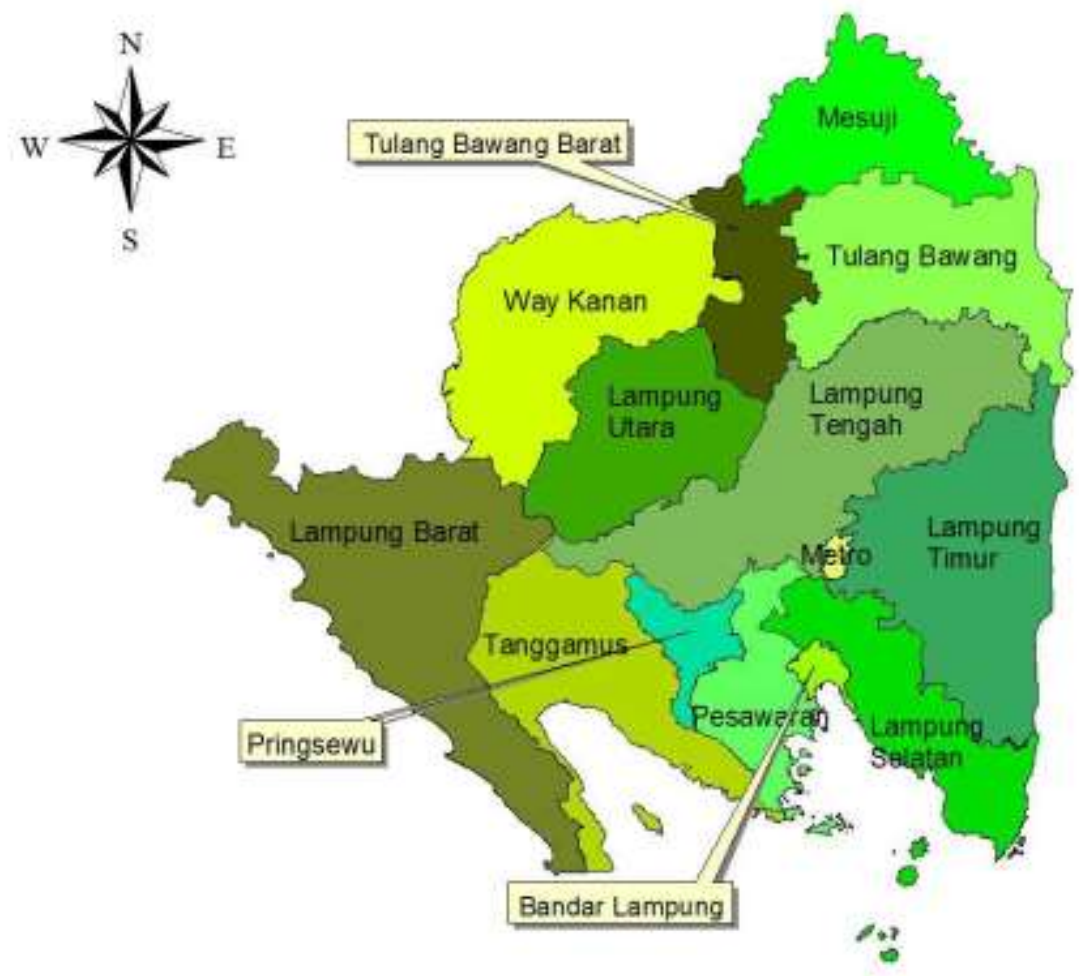

Gambar.1 Peta Provinsi Lampung

4. Analisis titik rawan kecelakaan menggunakan metode Cumulative Summary.

Cusum (Cummulative Summary) adalah suatu prosedur yang dapat digunakan untuk mengidentifikasi Black Spot. Grafik Cusum merupakan suatu prosedur statistik standar sebagai kontrol kualitas untuk mendeteksi perubahan dari nilai mean.

5. Kondisi inventarisasi titik rawan kecelakaan

Survei inventarisasi jalan dilakukan dengan maksud untuk mengetahui kondisi ruas jalan di wilayah studi. Kondisi yang diamati adalah meliputi panjang ruas, lebar, perkerasan jalan, tipe jalan, fasilitas dan perlengkapan jalan yang ada seperti rambu dan marka jalan.

6. Analisis konflik lalu lintas pada titik rawan kecelakaan

Survei dan analisis ini dimaksudkan untuk mengetahui pola pergerakan kendaraan yang menyebabkan kecelakaan lalu lintas

7. Rekomendasi penanganan titik rawan kecelakaan.

Rekomendasi penanganan pada daerah rawan kecelakaan yang diusulkan harus diterapkan dan dikoordinasikan oleh stakeholder pilar keselamatan guna mengurangi fatalitas kecelakaan dan menghilangkan daerah rawan kecelakaan. Rekomendasi dibuat berdasarkan hasil penentuan titik rawan kecelakaan pada ruas jalan tersebut agar tingkat kecelakaan di lokasi tersebut berkurang. 


\section{Hasil dan Pembahasan}

\subsection{Data Umum Kecelakaan di Provinsi Lampung}

Dalam pelaksanaan penelitian ini di BPTD Wilayah VI Bengkulu dan Lampung diperoleh data kecelakaan dari 13 kabupaten dan 1 kota yang ada di Provinsi Lampung, Seperti yang ditunjukkan pada Tabel .

Tabel 1. Jumlah Kecelakaan Lalu Lintas di Provinsi Lampung

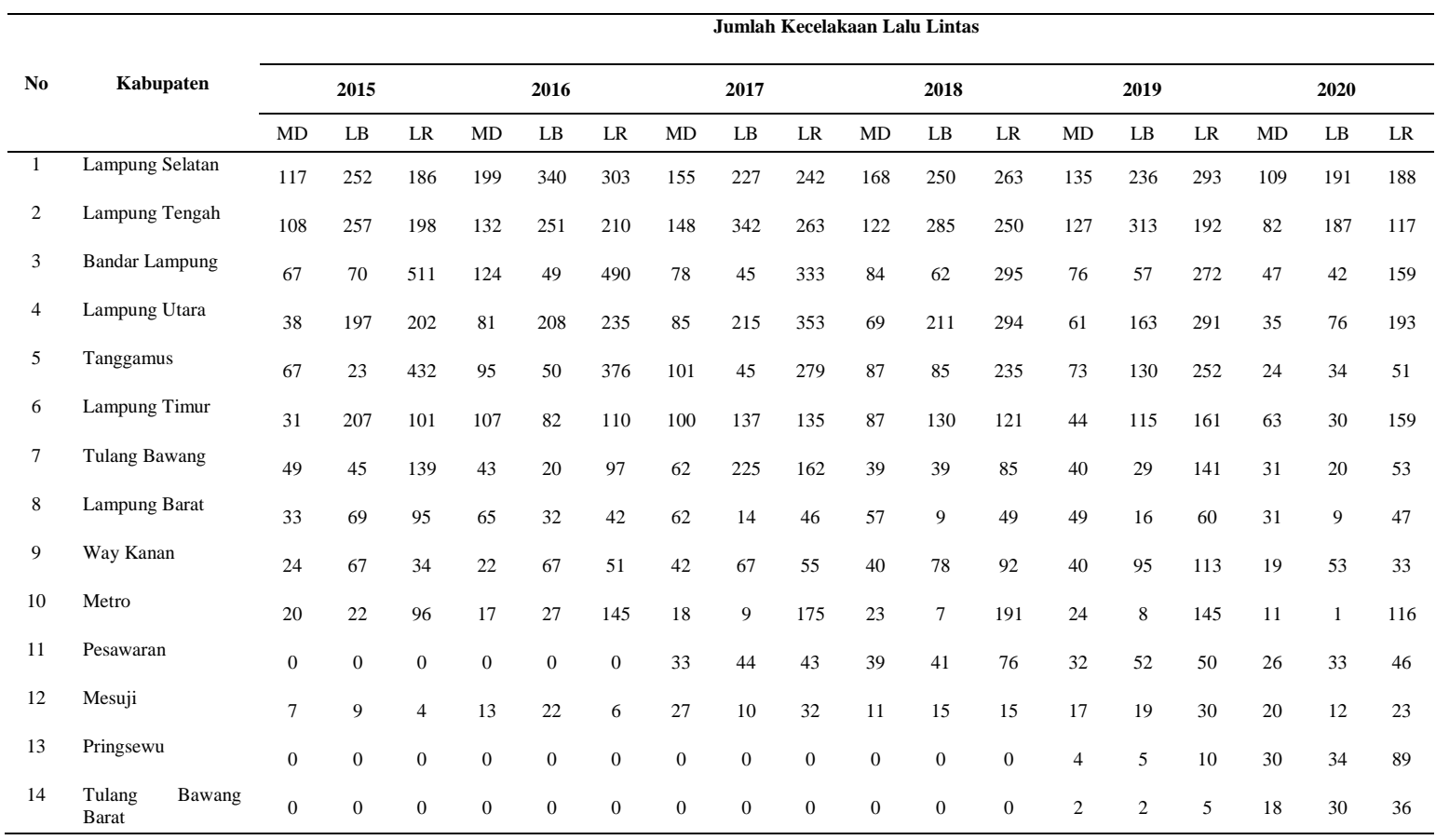

Sumber: Direktorat Lalu Lintas Polda Lampung, 2020

Berdasarkan Tabel 1 diatas diperoleh kecelakaan per-kabupaten/kota dapat disimpulkan bahwa urutan jumlah total kecelakaan terbanyak yang terjadi di Provinsi Lampung adalah Kabupaten Lampung Selatan.

\subsection{Profil Kecelakaan Kabupaten Lampung Selatan}

Jumlah kecelakaan dari tahun 2015-2020 di Kabupaten Lampung Selatan terdiri dari 3854 korban dengan spesifikasi 883 korban meninggal dunia, 1496 korban luka berat, dan 1475 korban luka ringan.

Berdasarkan Tabel 2 tingkat kecelakaan, tingkat kecelakaan dengan klasifikasi berat paling tinggi pada tahun 2016 dengan total kejadian 177 kecelakaan. Pada tingkat kecelakaan ringan paling tinggi pada tahun 2019 dengan total kejadian 54 kecelakaan. Pada tingkat kecelakaan sedang mengalami grafik fluktuatif dengan kejadian 170-180 kecelakaan selama 5 tahun terakhir.

Tabel 2. Data Kecelakaan Berdasarkan Tingkat Kecelakaan

\begin{tabular}{ccccccc}
\hline Klasifikasi & $\mathbf{2 0 1 5}$ & $\mathbf{2 0 1 6}$ & $\mathbf{2 0 1 7}$ & $\mathbf{2 0 1 8}$ & $\mathbf{2 0 1 9}$ & $\mathbf{2 0 2 0}$ \\
\hline Berat & 110 & 177 & 139 & 156 & 113 & 5 \\
Ringan & 11 & 13 & 15 & 36 & 54 & 16 \\
Sedang & 172 & 175 & 152 & 178 & 180 & 0 \\
Tidak Diketahui & 3 & 3 & 0 & 0 & 0 & 0 \\
\hline
\end{tabular}

Sumber: Hasil Analisis, 2000 


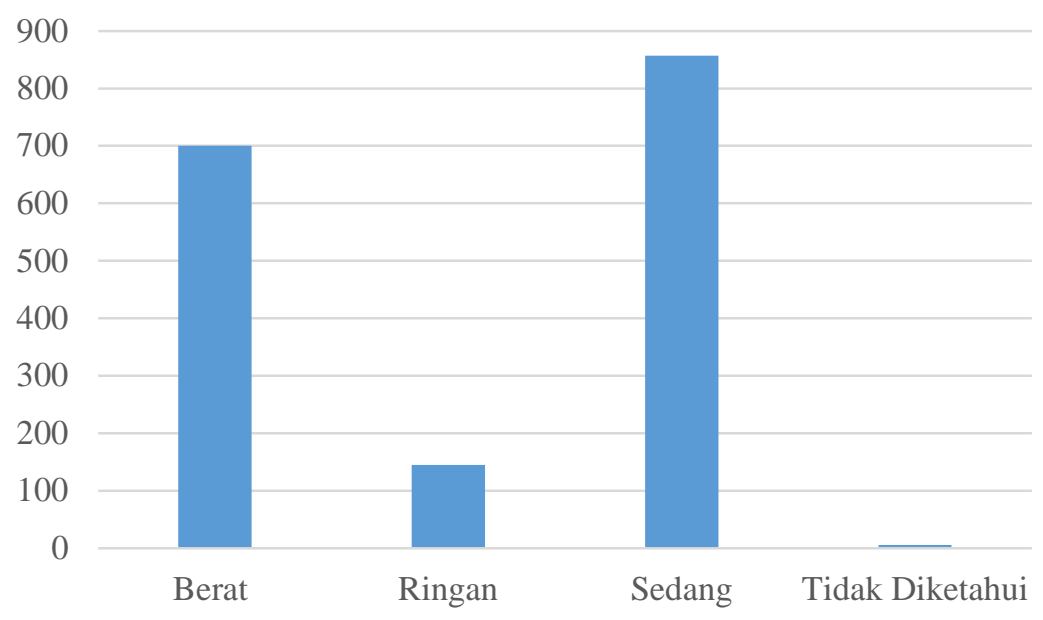

Gambar 2. Grafik Tingkat Kecelakaan di Lampung Selatan (Sumber: Hasil Analisis, 2020)

Berdasarkan grafik tingkat kecelakaan, tingkat kecelakaan terbesar adalah kecelakaan dengan klasifikasi sedang pada 5 tahun terakhir di Kabupaten Lampung Selatan.

\subsection{Analisis EAN}

Penentuan lokasi rawan kecelakaan berdasarkan hasil perhitungan angka kecelakaan yang memiliki nilai bobot (EAN) melebihi nilai batas tertentu, nilai pembobotan standar yang digunakan adalah meninggal dunia $(\mathrm{MD})=12$, luka berat $(\mathrm{LB})=6$, luka ringan $(\mathrm{LR})=3$, Kerusakan kendaraan $(\mathrm{K})=$ 1. Nilai batas ini dapat dihitung menggunakan metode Batas Kontrol Atas (BKA). Pada tahun 2015-2020 pada Provinsi Lampung teridentifikasi kecelakaan terjadi pada 97 ruas jalan pada tahun terakhir dengan 10 teratas ruas jalan kategori black link pada Tabel 3.

Tabel 3. Black Link dengan Metode EAN

\begin{tabular}{|c|c|c|c|c|c|c|c|c|}
\hline \multirow{2}{*}{ Nama Jalan } & \multicolumn{3}{|c|}{ AEK } & \multirow{2}{*}{$\begin{array}{c}\text { Jumlah } \\
\text { AEK }\end{array}$} & \multirow{2}{*}{$\mathbf{C}$} & \multirow{2}{*}{ UCL } & \multirow{2}{*}{ BKA } & \multirow{2}{*}{ Keterangan } \\
\hline & MD & LB & LR & & & & & \\
\hline Jalan Lintas Tengah & 1812 & 813 & 918 & 3543 & 113,9 & 142,7609 & 145,9577 & Blacklink \\
\hline Jalan Lintas Timur & 1788 & 678 & 690 & 3156 & 113,9 & 142,7609 & 145,9577 & Blacklink \\
\hline Jalan Ahmad Yani & 288 & 249 & 144 & 681 & 113,9 & 142,7609 & 145,9577 & Blacklink \\
\hline Jalan Ir Sutami & 336 & 96 & 63 & 495 & 113,9 & 142,7609 & 145,9577 & Blacklink \\
\hline $\begin{array}{l}\text { Jalan Jendral Sudirman } \\
\text { Jalan Lintas Pantai }\end{array}$ & 252 & 81 & 102 & 435 & 113,9 & 142,7609 & 145,9577 & Blacklink \\
\hline Timur & 84 & 42 & 33 & 159 & 113,9 & 142,7609 & 145,9577 & Blacklink \\
\hline Jalan Raya Way Ratay & 96 & 27 & 9 & 132 & 113,9 & 142,7609 & 145,9577 & Bukan \\
\hline Jalan Bumisari & 48 & 21 & 27 & 96 & 113,9 & 142,7609 & 145,9577 & Bukan \\
\hline $\begin{array}{l}\text { Jalan Gatot Subroto } \\
\text { Jalan Bojonegoro }\end{array}$ & 48 & 27 & 15 & 90 & 113,9 & 142,7609 & 145,9577 & Bukan \\
\hline Ngawi & 36 & 27 & 24 & 87 & 113,9 & 142,7609 & 145,9577 & Bukan \\
\hline
\end{tabular}

Sumber: Hasil Analisis, 2020 
Berdasarkan hasil analisis dengan menggunakan metode Equivalent Accident Number (EAN) tahun 2015-2020 didapatkan lokasi black link teratas dengan posisi pertama terletak pada Jalan Lintas Tengah.

\subsection{Metode Z-Score}

Analisis Z-Score yang dilakukan pada ruas jalan di Kabupaten Lampung Selatan ditemukan sebanyak 4 ruas dengan kategori black link. Berikut daftar ruas jalan kategori black link dengan analisis Z-score antara lain dapat dilihat pada Tabel 4.

Tabel 4. Black link dengan Metode Z-Score

\begin{tabular}{|c|c|c|c|c|c|c|c|c|c|}
\hline \multirow{2}{*}{ Nama Jalan } & \multicolumn{6}{|c|}{ Tahun } & \multirow{2}{*}{ Z } & \multirow{2}{*}{ Kriteria } & \multirow{2}{*}{ Rank } \\
\hline & 2015 & 2016 & 2017 & 2018 & 2019 & 2020 & & & \\
\hline Jalan Lintas Tengah & 140 & 41 & 16 & 0 & 145 & 10 & 6,976846 & Blacklink & 1 \\
\hline Jalan Lintas Timur & 28 & 134 & 1 & 96 & 23 & 0 & 5,544199 & Blacklink & 2 \\
\hline Jalan Ahmad Yani & 42 & 33 & 0 & 0 & 0 & 0 & 1,307656 & Blacklink & 3 \\
\hline Jalan Ir Sutami & 0 & 18 & 0 & 0 & 10 & 3 & 0,407135 & Blacklink & 4 \\
\hline Jalan Insinyur Sutami & 11 & 0 & 0 & 0 & 0 & 0 & $-0,00219$ & Bukan & 5 \\
\hline Jalan Raya Way Ratay & 0 & 10 & 0 & 0 & 0 & 0 & $-0,02266$ & Bukan & 6 \\
\hline Jalan Gatot Subroto & 0 & 9 & 0 & 0 & 0 & 0 & $-0,04313$ & Bukan & 7 \\
\hline Jalan Lintas Barat & 0 & 5 & 3 & 0 & 0 & 0 & $-0,06359$ & Bukan & 8 \\
\hline Jalan Branti & 3 & 0 & 0 & 0 & 5 & 0 & $-0,06359$ & Bukan & 9 \\
\hline Jalan Katipung Raya & 2 & 2 & 0 & 0 & 4 & 0 & $-0,06359$ & Bukan & 10 \\
\hline
\end{tabular}

Sumber: Hasil Analisis, 2020

\subsection{Metode Frekuensi}

Analisis menggunakan metode frekuensi yang dilakukan pada ruas jalan di Kabupaten Lampung Selatan ditemukan sebanyak 4 ruas dengan kategori black link. Berikut daftar ruas jalan kategori black link dengan analisis frekuensi antara lain dapat dilihat pada Tabel 5.

Tabel 5. Black link dengan Metode Frekuensi

\begin{tabular}{|c|c|c|c|c|c|c|c|c|c|}
\hline \multirow{2}{*}{ Nama Jalan } & \multicolumn{6}{|c|}{ Tahun } & \multirow[b]{2}{*}{ Jumlah } & \multirow[b]{2}{*}{ KeT } & \multirow{2}{*}{ Rank } \\
\hline & 2015 & 2016 & 2017 & 2018 & 2019 & 2020 & & & \\
\hline Jalan Lintas Tengah & 140 & 41 & 16 & 0 & 145 & 10 & 352 & Blacklink & 1 \\
\hline Jalan Lintas Timur & 28 & 134 & 1 & 96 & 23 & 0 & 282 & Blacklink & 2 \\
\hline Jalan Ahmad Yani & 42 & 33 & 0 & 0 & 0 & 0 & 75 & Blacklink & 3 \\
\hline Jalan Ir Sutami & 0 & 18 & 0 & 0 & 10 & 3 & 31 & Blacklink & 4 \\
\hline Jalan Insinyur Sutami & 11 & 0 & 0 & 0 & 0 & 0 & 11 & Bukan & 5 \\
\hline Jalan Raya Way Ratay & 0 & 10 & 0 & 0 & 0 & 0 & 10 & Bukan & 6 \\
\hline Jalan Gatot Subroto & 0 & 9 & 0 & 0 & 0 & 0 & 9 & Bukan & 7 \\
\hline Jalan Lintas Barat & 0 & 5 & 3 & 0 & 0 & 0 & 8 & Bukan & 8 \\
\hline Jalan Branti & 3 & 0 & 0 & 0 & 5 & 0 & 8 & Bukan & 9 \\
\hline Jalan Katipung Raya & 2 & 2 & 0 & 0 & 4 & 0 & 8 & Bukan & 10 \\
\hline
\end{tabular}

Sumber: Hasil Analisis, 2020 


\subsection{Kondisi Umum Jalan Lintas Tengah Sumatera}

Ruas Jalan Lintas Tengah Sumatera merupakan salah satu jalan utama yang dilalui kendaraan ke berbagai tujuan. Jalan tersebut merupakan jalan provinsi yang menghubungkan Kota Bandar Lampung ke arah Bakauheni. Berdasarkan klasifikasi muatan sumbu, Jalan Lintas Tengah Sumatera merupakan jalan kelas II yang biasanya dilalui kendaraan angkutan umum maupun peti kemas. Ruas jalan ini menurut fungsinya diklasifikasikan sebagai jalan arteri. Jalan arteri adalah jalan yang melayani angkutan utama dengan ciri - ciri perjalanan jarak jauh, kecepatan rata - rata tinggi, dan jumlah jalan masuk dibatasi secara berdaya guna. Kapasitas ruas Jalan Lintas Tengah Sumatera diketahui berdasarkan Tabel 6 yaitu:

Tabel 6. Analisis Kapasitas Jalan Lintas Tengah Sumatera

\begin{tabular}{ccc}
\hline Faktor Penyesuaian & Hasil Survei & Koefisien \\
\hline Co & Empat lajur terbagi & 1650 \\
FCw & 3 & 0,92 \\
FCsp & $50-50$ & 1,00 \\
FCsf & L & 0,97 \\
FCcs & $0,1-0,3$ & 1,00 \\
\hline
\end{tabular}

Sumber: Hasil Analisis, 2020

$\mathrm{C}$ : Kapasitas (smp/jam); Co : Kapasitas dasar (smp/jam); FCw : Faktor penyesuaian lebar jalur lalu lintas; FCsp : Faktor penyesuaian pemisah arah; FCsf : Faktor penyesuaian hambatan samping; FCcs : Faktor penyesuaian ukuran kota

$\mathrm{C}=\mathrm{Co} \times \mathrm{FCw} \times \mathrm{FCsp} \times \mathrm{FCsf} \times \mathrm{FCcs}(\mathrm{smp} / \mathrm{jam})$

$=1650 \times 0,92 \times 1 \times 0,97 \times 1=1472,46 \mathrm{smp} / \mathrm{jam}$

Tabel 7. Kinerja Ruas Jalan Lintas Tengah Sumatera

\begin{tabular}{cccc}
\hline $\begin{array}{c}\text { Arus Lalu } \\
\text { Lintas } \\
\text { Q (smp/jam })\end{array}$ & Kapasitas & Derajat Kejenuhan & $\begin{array}{c}\text { Tingkat } \\
\text { Pelayanan } \\
\text { LoS }\end{array}$ \\
\hline 3571 & $\mathrm{C}$ & $\mathrm{DS}$ & $\mathrm{C}$ \\
\hline
\end{tabular}

Sumber: Hasil Analisis, 2020

Berdasarkan hasil analisis data, tingkat pelayanan pada Jalan Lintas Tengah Sumatera adalah kategori C yaitu selaras dengan kondisi Jalan Lintas Tengah Sumatera yang memiliki ciri-ciri arus stabil, tetapi kecepatan dan gerak kendaraan dikendalikan, serta pengemudi dibatasi dalam memilih kecepatan kendaraan yang dikendarai nya.

Kondisi Jalan Lintas Tengah Sumatera yang lurus dan lebar membuat pengemudi yang melewati ruas jalan tersebut cenderung memacu kendaraannya dengan kecepatan yang tinggi sehingga berpotensi menimbulkan bahaya bagi pengguna jalan yang lain. Selain itu kondisi marka jalan yang pudar, lampu PJU yang tidak ada, dan beberapa problematika pada perlengkapan jalan membuat pengemudi kesulitan memperoleh informasi jalan di malam hari. Berdasarkan hasil analisis yang telah dilakukan, dengan mengacu pada data kecelakaan tahun 2016-2020 yang telah diolah didapatkan hasil bahwa ruas Jalan Lintas Tengah Sumatera teridentifikasi sebagai lokasi rawan kecelakaan. Oleh karena itu, perlu adanya penentuan titik rawan kecelakaan pada ruas jalan tersebut untuk memudahkan analisis titik rawan kecelakaan dan memudahkan untuk memberikan rekomendasi penanganan agar tingkat kecelakaan di lokasi tersebut berkurang. 
Tabel 8. Titik Black spot di ruas Jalan Lintas Tengah Sumatera

\begin{tabular}{cccc}
\hline \multicolumn{2}{l}{ Jalan Lintas Tengah Sumatera } & \multirow{2}{*}{ Kriteria } & \multirow{2}{*}{ Rank } \\
\cline { 1 - 3 } STA & Kejadian Kecelakaan & \\
\cline { 1 - 3 } KM 17-18 & 6 & Blackspot & 5 \\
KM 18-19 & 8 & Blackspot & 2 \\
KM 21-22 & 7 & Blackspot & 3 \\
KM 23-24 & 9 & Blackspot & 1 \\
KM 25-26 & 7 & Blackspot & 4 \\
\hline
\end{tabular}

Sumber: Hasil Analisis, 2020

Dalam melakukan identifikasi black spot sepanjang ruas Jalan Lintas Tengah Sumatera dilakukan pembagian segmen $1 \mathrm{KM}$. Dari hasil pembagian tiap segmen kemudian dilakukan penghitungan menggunakan metode Cumulative Summary (Cussum) sebagaimana dapat dilihat pada tabel 8 .

Berdasarkan tabel tersebut, black spot di Jalan Lintas Tengah Sumatera berada pada KM 18-26 dengan rincian rank pertama pada KM 23-24, kedua KM 18-19, ketiga KM 21-22, keempat 25-26, kelima 17-18.

\subsection{Kondisi Inventarisasi Jalan Lintas Tengah Sumatera}

Kondisi jalan dan perlengkapan jalan sangat berpengaruh terhadap terjadinya kecelakaan. Kondisi eksisting jalan dalam survei inventarisasi jalan antara lain pada Tabel 9.

Tabel 9. Kondisi Eksisting Jalan

\begin{tabular}{ll}
\hline \multicolumn{1}{c}{ Klasifikasi } & \multicolumn{1}{c}{ Kondisi Eksisiting } \\
\hline Kelas jalan & Kelas II \\
Fungsi jalan & Jalan arteri \\
Jenis perkerasan & Perkerasan kaku (rigid pavement) \\
Tipe jalan & $4 / 2 \mathrm{D}$ \\
Lebar jalur & $13,5 \mathrm{~m}$ \\
Lebar bahu jalan & $1 \mathrm{~m}$ (Hanya di ruas jalan ke arah Bakauheni) \\
Jenis median/separator & Water barrier $($ lebar: $70 \mathrm{~cm})$ \\
Lebar drainase & $0,60 \mathrm{~m}$ \\
Kedalaman drainase & $0,90 \mathrm{~m}$ \\
Tipe drainase & Terbuka \\
\hline Sumber: Hasil Analisis, 2020 &
\end{tabular}

Jalan Lintas Tengah Sumatera memiliki panjang $218 \mathrm{~km}$. Jalan tersebut pada KM 18-26 memilki geometri jalan naik-turun tepatnya pada KM 20-21. Ditinjau dari kondisi geometri jalannya, pada lokasi black spot di Jalan Lintas Tengah Sumatera memiliki kondisi geometri jalan yang memiliki banyak tikungan. Sebagian besar jalan pada ruas tersebut menanjak dan menurun. Kondisi geometri ini merupakan salah satu faktor penyebab terjadinya kecelakaan. Ketika malam hari dengan kondisi jalan yang sepi dan gelap akibat lampu PJU yang mati cenderung membuat pengemudi penglihatan terbatas. Hal tersebut di dukung medan jalan yang banyak tikungan menanjak dan menurun membuat kecelakaan sering terjadi.

\subsection{Konflik Lalu Lintas}

Pada pengamatan titik rawan kecelakaan dilakukan survei konflik lalu lintas. Terjadinya konflik lalu lintas banyak terjadi di persimpangan baik simpang bersinyal maupun simpang tidak bersinyal. 
Seperti hal nya di KM 20-21 terdapat persimpangan yang masuk ke arah Pantai Sebalang. Hal inilah yang menimbulkan adanya konflik lalu litas di ruas Jalan Lintas Tengah Sumatera. Survei konflik lalu lintas ini hanya berfokus pada jenis konflik dan juga jumlah konflik lalu lintas. Berdasarkan hasil pengamatan di lokasi survei, berikut merupakan konflik lalu lintas yang terjadi pada KM 20-21 Jalan Lintas Tengah Sumatera pada Tabel 10.

Tabel 10. Jenis Konflik Kecelakaan di Jalan Lintas Tengah Sumatera

\begin{tabular}{cccc}
\hline Jenis Konflik & Ke Arah Bakauheni & Ke Arah Bandar Lampung & Ke Pantai Sebalang \\
\hline Crossing & 10 & 5 & 12 \\
Merging & 4 & 6 & 0 \\
Diverging & 6 & 4 & 5 \\
Weaving & 7 & 5 & 2 \\
\hline
\end{tabular}

Sumber: Hasil Analisis, 2020

Berdasarkan Tabel 10 dapat diketahui bahwa konflik lalu lintas yang sering terjadi adalah konflik diverging dan crossing. Hal ini dikarenakan adanya kendaraan yang masuk ke Pantai Sebalang dan juga menuju arah Bandar Lampung dari ruas Jalan Sebalang. Data dari konflik lalu lintas yang telah didapatkan, maka dapat dilakukan analisa berdasarkan jenis konflik lalu lintas yang terjadi di lokasi pengambilan data konflik. Berikut merupakan gambaran terjadinya konflik lalu lintas pada sebuah akses keluar masuk kendaraan.

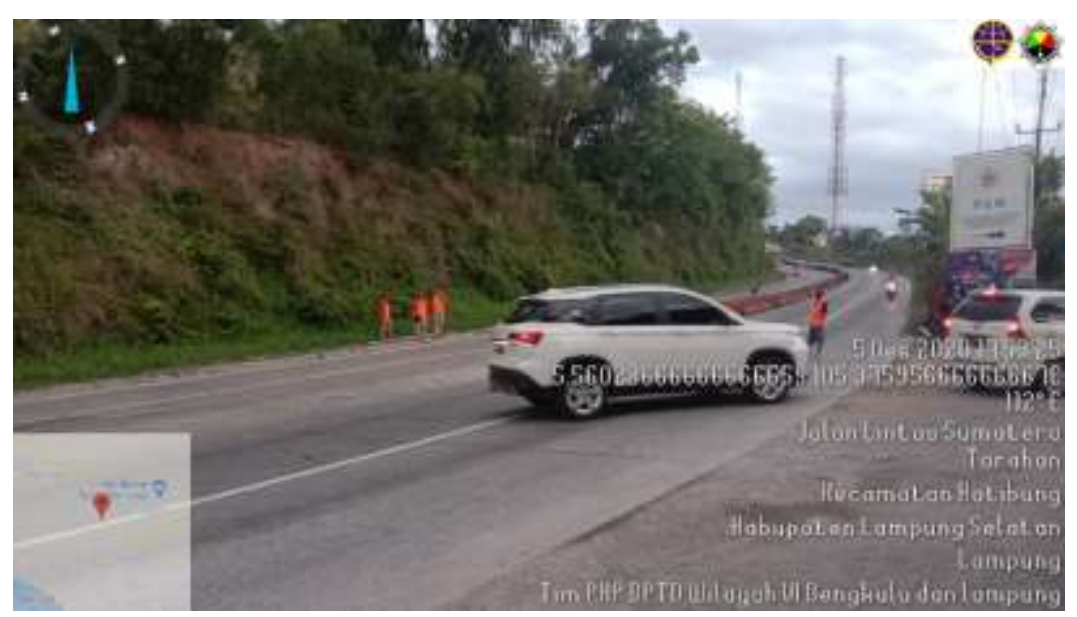

Gambar 3. Kondisi Simpang Sebalang

Konflik lalu lintas yang terjadi di ruas Jalan Lintas Tengah Sumatera menjadi salah satu faktor penyebab kecelakaan ketika ada kendaraan yang melaju dengan kecepatan yang tinggi ke arah Bandar Lampung. Simpang tersebut juga merupakan simpang tidak bersinyal yang terletak saat jalan menurun.

\subsection{Rekomendasi Penanganan Titik Rawan Kecelakaan}

Berdasarkan hasil analisis DRK, rekomendasi yang diharapkan adalah kebutuhan fasilitas keselamatan seperti perlengkapan jalan. Jumlah perlengkapan jalan yang direkomendasikan adalah rambu peringatan sebanyak 53, rambu larangan sebanyak 3, rambu petunjuk sebanyak 15 , zebra cross sebanyak 5, warning light sebanyak 1, water barrier sebanyak 2, dan PJU sebanyak 2. 


\section{Kesimpulan}

Kecelakaan paling tinggi di Provinsi Lampung adalah Kabupaten Lampung Selatan. Tingkat fatalitas mencapai 2,215\%. Indeks fatalitas di Kabupaten Lampung Selatan dari rentang waktu 2017-2020 paling tinggi terjadi pada tahun 2019 sebesar 2,57\%. Berdasarkan hasil analisis dengan menggunakan 4 metode penentuan daerah rawan kecelakaan (DRK) dan perankingan DRK tiap status jalan dari 93 ruas jalan terdapat 1 jalan yang merupakan black link tertinggi dari setiap status jalan yaitu Jalan Lintas Tengah Sumatera dengan titik rawan kecelakaan KM 18-26 dengan rincian rank pertama pada KM 23-24 yang memilki geometri jalan naik-turun tepat pada KM 20-21. Berdasarkan hasil analisis daerah rawan kecelakaan, rekomendasi yang diharapkan adalah kebutuhan fasilitas keselamatan seperti perlengkapan jalan.

\section{Daftar Pustaka}

Arumsari, N., Nugraha, A., \& Awaluddin, M. (2016). Pemodelan Daerah Rawan Kecelakaan Dengan Menggunakan Cluster Analysis (Studi Kasus: Kabupaten Boyolali). Jurnal Geodesi Undip.

Direktorat Lalu Lintas Polda Lampung. (2020). Data Laka Lantas Jajaran Polda Lampung 20152020.

Fan, Z., Liu, C., Cai, D., \& Yue, S. (2019). Research on black spot identification of safety in urban traffic accidents based on machine learning method. Safety Science. https://doi.org/10.1016/j.ssci.2019.05.039

Ghadi, M., \& Török, Á. (2017). Comparison Different Black Spot Identification Methods. Transportation Research Procedia. https://doi.org/10.1016/j.trpro.2017.12.104

Gregoriades, A., \& Mouskos, K. C. (2013). Black spots identification through a Bayesian Networks quantification of accident risk index. Transportation Research Part C: Emerging Technologies. https://doi.org/10.1016/j.trc.2012.12.008

Herawati, H. (2019). Karakteristik Dan Penyebab Kecelakaan Lalu Lintas Di Indonesia Tahun 2012. Warta Penelitian Perhubungan. https://doi.org/10.25104/warlit.v26i3.875

Hidayat, D. W., \& Oktopianto, Y. (2020). Peningkatan Kinerja Simpang Tiga Bersinyal Studi Kasus Simpang Tiga Purin Kendal. Jurnal Keselamatan Transportasi Jalan (Indonesian Journal of Road Safety), 7(2), 36-45. https://doi.org/10.46447/ktj.v7i2.289

Isa Al Qurni. (2016). Analisis Daerah Rawan Kecelakaan Lalu Lintas (Studi Kasus Jalan Nasional Arteri Primer Dan Arteri Sekunder Kabupaten Kendal). Jurnal Geografi : Media Informasi Pengembangan Dan Profesi Kegeografian. https://doi.org/10.15294/jg.v13i1.7989

Khomeini, M., \& Taufik, S. (2017). Analisis Penanganan Lokasi Rawan Kecelakaan Lalu Lintas Di Kota Palangka Raya. Jurnal Teknologi Berkelanjutan (Sustainable Technology Journal).

Rahmawaty, T. A., Kriswardhana, W., Widiarti, W. Y., \& Sulistyono, S. (2020). Analisis Karakteristik Kecelakaan di Ruas Jalan Gadjah Mada Kabupaten Jember. Borneo Engineering: Jurnal Teknik Sipil, 4(1), 113-125.

Sandhyavitri, A., Zamri, Wiyono, S., \& Subiantoro. (2017). Three Strategies Reducing Accident Rates at Black Spots and Black Sites Road in Riau Province, Indonesia. Transportation Research Procedia. https://doi.org/10.1016/j.trpro.2017.05.415 
Utomo, N. (2012). Analisa Faktor Penyebab Kecelakaan Lalu Lintas Pada Segmen Jalan By-Pass Krian-Balongbendo (Km. 26+000-Km. 44+520). Jurnal Teknik Sipil KERN.

W/Yohannes, A. Y., \& Minale, A. S. (2015). Identifying the hot spot areas of road traffic accidents. Jordan Journal of Civil Engineering. https://doi.org/10.14525/jjce.9.3.3077

Wakabayashi, H., Ando, M., Kawaguchi, T., Horie, Y., \& Hotta, K. H. (2014). Sustainable traffic safety management at accident black spots combined with drivers' psychology and vehicle engineering using eye mark recorder. Transportation Research Procedia. https://doi.org/10.1016/j.trpro.2014.10.094

Zulhendra. (2015). Jurnal analisis tingkat kecelakaan lalu lintas pada ruas jalan propinsi sta $\mathrm{km}$ 190-240 (simpang kumu-kepenuhan). Jurnal Tehnik Sipil. 